Symposium on 'Perspectives in the study of food intake'

\title{
The evolution of the control of food intake
}

\author{
A. W. Illius ${ }^{1 *}$, B. J. Tolkamp ${ }^{2}$ and J. Yearsley ${ }^{3}$ \\ ${ }^{1}$ Institute of Cell, Animal and Population Biology, University of Edinburgh, West Mains Rd, Edinburgh EH9 3JT, UK \\ ${ }^{2}$ Animal Nutrition and Health Department, Animal Biology Division, Scottish Agricultural College, West Mains Road, \\ Edinburgh EH9 3JG, UK \\ ${ }^{3}$ Macaulay Land Use Research Institute, Craigiebuckler, Aberdeen AB15 8QH, UK
}

\begin{abstract}
The ultimate goal of an organism is to maximise its inclusive fitness, and an important sub-goal must be the optimisation of the lifetime pattern of food intake, in order to meet the nutrient demands of survival, growth and reproduction. The conventional assumption that fitness is maximised by maximising daily food intake, subject to physical and physiological constraints, has been challenged recently. Instead, it can be argued that fitness is maximised by balancing benefits and costs over the organism's lifetime. The fitness benefits of food intake are a function of its contribution to survival, growth (including necessary body reserves) and reproduction. Against these benefits must be set costs. These costs include not only extrinsic foraging costs and risks, such as those due to predation, but also intrinsic costs associated with food intake, such as obesity and oxidative metabolism that may reduce vitality and lifespan. We argue that the aggregate of benefits and costs form the fitness function of food intake and present examples of such an approach to predicting optimal food intake.
\end{abstract}

Food intake: Linear programming: Cost-benefit: Fitness

The consumption of food is one of the most fundamental activities in all animals, including livestock and humans. Evolutionary theory tells us that the ultimate goal of an organism is to maximise its inclusive fitness, and an important sub-goal must be the optimisation of the lifetime pattern of food intake, in order to meet the nutrient demands of survival, growth and reproduction. The ways that animals have evolved to link their foraging behaviour to its nutritional and functional outcome form the context for the evolution of the underlying molecular and physiological effector mechanisms that control food intake in the short term. The reductionist approach to research on the mechanisms themselves addresses the question of how food intake is controlled. However, studies are also needed of feeding behaviour in the light of the organism's evolutionary background, in order to help us understand why it responds as it does in particular circumstances.

This approach seems particularly relevant to the understanding of the feeding behaviour of humans and livestock in modern environments. These environments frequently offer ready access to high-quality foods at greatly reduced needs for energy expenditure. We cannot expect to be able to interpret and understand the responses of animals and humans living in artificial or controlled environments unless we take an evolutionary and goal-oriented approach to the problem, and address the sort of challenges that the organism has evolved to meet.

\section{Fitness and its proxies}

Foraging behaviour has been the subject of extensive theoretical and empirical research (for example, see Stephens \& Krebs, 1986). It is assumed that an animal that can forage more effectively than others will be at an advantage in allocating acquired resources to survival and reproduction. Natural selection will lead, therefore, to the evolution of morphological, physiological and behavioural adaptations to the animal's environment. The study of 
adaptation is an integral part of evolutionary biology, and seeks to relate variation in a character to variation in fitness. Since fitness cannot easily be studied directly, it is usual in foraging theory to choose a convenient proxy for fitness. Thus, when comparing alternative foraging strategies, it may be assumed that the one that maximises the rate of energy intake during foraging will, other things being equal, maximise fitness. This approach has led to notable advances when the focus of inquiry has been behaviour during foraging, such as optimal diet selection or optimal patch use. However, there have been relatively few inquiries into when an animal should stop foraging, and so we know little of the theoretical determinants of optimal daily food intake.

If we take the maximisation of energy intake rate to be a proxy for the fitness consequences of eating, then we must invoke some sort of constraint, otherwise the solution would be unbounded. Thus, constraints are a logical necessity of the assumption that animals seek to maximise food intake. For example, the classical linear programming (LP) model of diet choice (Belovsky, 1978) uses constraints on digestive capacity and foraging time to define the energy-maximising quantities of two (or more) dietary ingredients. This model is very successful, judged by the accuracy of its predictions and by its wide application (in over 400 published studies; Belovsky, 1994). LP uses fixed constraints to set boundaries on the feasible solution space, and the optimal solution is always located at one of the vertices of this space. Such a model portrays the animal as living at the edge of the envelope, and presupposes that the constraints are limits that cannot be breached. To apply this model, we would need good a priori grounds to believe that the chosen constraints do really operate as limits, and establishing this evidence is not nearly as easy as it might seem. A number of problems with this approach, discussed later, suggest to us that intake maximisation subject to constraints is an inappropriate model of what controls daily food intake.

\section{Intake maximisation subject to constraints}

Theories that incorporate the concept of constraint have weaknesses that stem from the vagaries, imprecision and difficulties of applying constraints in a meaningful way.

\section{What is a constraint?}

Narrowly defined, constraints are fixed limits that cannot be breached and may be immutable, such as the sum of resources allocated to competing alternatives cannot exceed the total resources available, or the number of hours spent writing scientific papers per $\mathrm{d} \leq 24$. Such constraints can sometimes be implicit, as for example, in the trade-off between offspring numbers and viability. In this case, as offspring numbers increase, per capita resource allocation to them will decline, because of the implicit constraint that total resources are fixed. It can easily be shown that the optimal proportional allocation of resources to competing fitness-generating actions is a function of the quantity of resources available. In this case the quantity of resources, which is a constraint from one viewpoint, is a parameter.

Problems of definition also occur when comparing constraints across timescales and levels. A character such as beak length might be regarded as a constraint on the depth that a bird can probe into mud for prey, but given that the trait is heritable and that there is genetic variation in the trait, natural selection may operate on it such that, in time, the length increases. To someone working on an individual's foraging behaviour, beak length is a fixed constraint, or it may be a parameter in a model, while to an evolutionist it may be a variable.

The problem of the level at which something is viewed as a constraint goes beyond the mere question of definition. Fig. 1 describes a number of levels at which optimisation or trade-offs are taking place in the maximisation of fitness, here defined as rearing the maximum number of offspring surviving to reproductive age. The scheme shows the flow of resources through a series of allocation decisions, each of which is constrained by the amount of resources made available from lower levels. Thus, what might be regarded as constraints at one level are actually the outcome of tradeoffs at lower levels. It might seem to be reasonable to address each allocation problem in isolation if one wishes, provided that the levels are truly independent. However, in some cases they are clearly not, as in the example (Fig. 1) where avoiding mortality risks of foraging and allocation to somatic repair and other longevity-increasing measures both have an effect on reproductive lifespan. We should really regard the scheme in Fig. 1 as a network of interconnected trade-offs with a global optimum, which means that none of the resource flows can truly be regarded as a fixed constraint.

\section{Identifying constraints and causation}

The foremost difficulty in defining constraints is that of finding clear evidence that some particular character is actually constraining. Although there must be some extreme

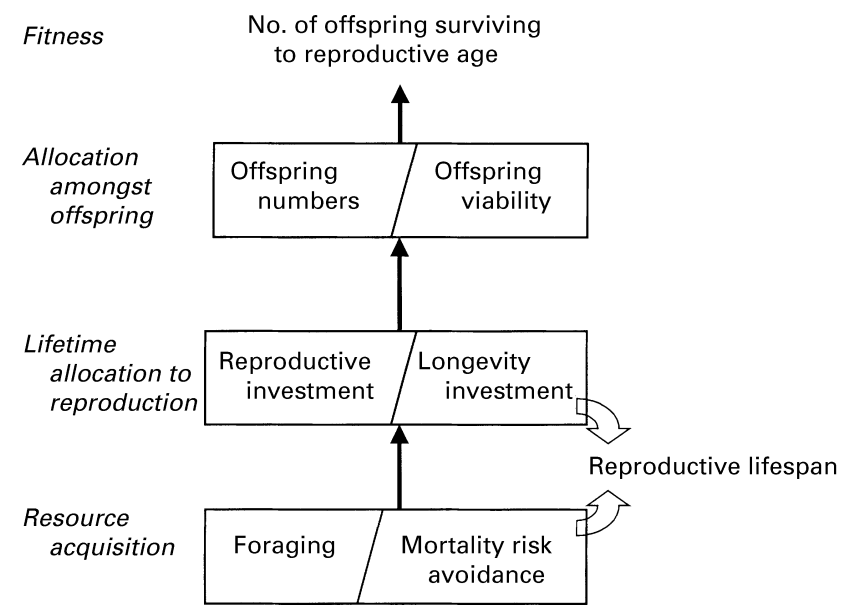

Fig. 1. Resources available from foraging are allocated to reproduction and between offspring to maximise fitness. Trade-offs, for example between allocating resources to large numbers of offspring numbers at the expense of per capita resource allocation to each individual offspring, are represented by the pairs separated by a diagonal line. Constraints at one level are the outcome of trade-offs at lower levels. $\rightarrow$, Flow of resources through a series of allocation decisions. 
values of digestive capacity and foraging time, for example, beyond which the animal cannot go, it is not clear that the values ordinarily observed in animals are anywhere near those limits. Merely to observe a high value of some character is not to show that it is either a maximum or acting as a limit. Indeed, whether or not digestive capacity does, in fact, limit intake in mammalian herbivores is hotly disputed by some nutritional physiologists, despite decades of research (for example, see Tolkamp \& Ketelaars, 1992; Allen, 1996; Weston, 1996; Pitroff \& Kothman, 1999). An alternative is that some other process limits or determines intake, and digestive capacity is merely the expression of that process.

Owen-Smith (1994, 1996, 1998) suggested that, in variable environments, animals may experience upper limits to their digestive capacity, thermal tolerance and foraging times only intermittently, under extreme conditions. Such conditions might exist at the end of the dry season and during droughts, when we would expect selection pressure on constraining components of foraging behaviour to be most acute. Conversely, animals will be able to live well within these limits at other times of the year, when values of digestive capacity and foraging time are not likely to be constraining. Does this interpretation mean that energy maximisation subject to constraints is the wrong model, or that constraints are elastic and continually changing and, hence, almost impossible to measure?

In general, it is observed that hunger increases the intake of animals, and it appears that factors thought to limit intake rate in some animals are overcome in hungrier ones (Illius \& Gordon, 1999). An example is provided by Gross et al. (1996), who studied the effect of reproductive status on food intake of female Nubian ibex (Capra ibex nubiana) that were offered grass or lucerne (Medicago sativa) hays (Table 1). The daily food and energy intake of non-lactating animals provided only slightly more than the animals required to maintain their body weight. Under the energetic burden of lactation, animals ate more food, and up to $50 \%$ more energy. In doing so, they increased the mass of food in their digestive tracts by up to twofold, and also increased mean retention time of digesta in the gastrointestinal tract. This response illustrates the plasticity, in the face of changing energy demand, of the two components traditionally used to calculate the digestive constraint. It seems to be an impossible case to argue that the food intake of the non-lactating ibex was constrained by digestive capacity, given that lactating ibex were able to expand that capacity to accommodate greater energy requirements.
It cannot be postulated that animals with different energy demands (resulting from particular reproductive states, different stages of the season cycle of fat depletion and repletion, needs for thermoregulation, etc.) are all energy maximisers subject to digestive constraints, unless the latter all take different values as a function of energy demand. That approach would put the cart before the horse; energy demand would determine the 'constraint', instead of the constraint determining energy supply. The predictive value of the model would also be poor, and it would be easier to measure intake directly than the constraint values needed to predict it.

\section{Specifying the constraints: Circular programming?}

Formidable practical difficulties arise from doubts about whether constraints are accurately identified and actually constraining. First, the experimenter can never be sure that values observed in the field are extreme values that operate as limits. Obviously, ultimate limits to digestive capacity and foraging time must exist, and if intake is actually constrained by these factors, then it will be possible to find the constraint values by observation. Problems of individual, seasonal and diurnal variation remain to be overcome.

Second, if a character or activity is wrongly assumed to define intake, observation of the values normally exhibited in foraging animals may be taken, erroneously, to be constraining values. Ironically, this approach does not impair the predictive value of the LP model using such 'constraints', as Owen-Smith (1993, 1996) showed. Suppose that food intake is determined by an unidentified constraint, such as tolerance of plant secondary compounds, or by nutrient imbalance, or by a trade-off such as between foraging and predation risk. Either or both foraging time and digestive capacity are likely, barring coincidence, to be submaximal, being expressions of the underlying decision process rather than determinants of it. However, when measured in the field and applied in LP, they will give rise to a spurious 'constraint' line that will nevertheless intersect with the average diet. Predicted diets will therefore match observed ones. It matters not that observations of 'constraint' values used to predict diets and observations of diets to test predictions are made from wholly independent sources; the circularity rests in assuming what constraints apply. The debate about the circularity of LP (Owen-Smith, 1993, 1994, 1996; Belovsky \& Schmitz, 1993; Belovsky et al. 1999) is not about the independence of data used to

Table 1. Intake and digestive capacity in ibex (Capra ibex nubiana; Gross et al. 1996)

\begin{tabular}{lccccc}
\hline Food type & Intake $(\mathrm{g} \mathrm{DM} / \mathrm{d})$ & Digestibility & Energy intake $(\mathrm{MJ} / \mathrm{d})$ & Digesta load* $(\mathrm{g}$ DM) & Rumen mean retention time $(\mathrm{h})$ \\
\hline Non-lactating & & & & & 583 \\
$\quad$ Grass hay & 632 & 0.66 & 12.9 & 439 & 20.8 \\
Lucerne† hay & 540 & 0.64 & 10.8 & & 19.2 \\
Lactating & & & 14.9 & 831 & 31.0 \\
$\quad$ Grass hay & 732 & 0.67 & 16.3 & 917 & 28.9 \\
Lucerne† hay & 866 & 0.62 & & \\
\hline
\end{tabular}

*Whole tract.

†Medicago sativa. 
formulate predictions and make observations. It is about whether the assumed constraints are constraining. If the experimenter believes that animals are energy maximisers (or time minimisers, for that matter), then something must constrain intake, and field measures of any candidate constraints will intersect with the average diet, even if they are merely the expression of some other underlying mechanism determining intake. As Owen-Smith (1996) states: '...the average digestive fill and average daily foraging time must correspond with the average dietary composition, whatever the constraints that are effective.' Predictive power is not, therefore, a test of the validity of LP as a description of what governs foraging behaviour and diet choice.

\section{An alternative paradigm: goal-seeking, costs and benefits}

The heuristic value of models lies not in their ability to make accurate predictions, but in their ability to make predictions for the right reasons. We suggest that fitness maximisation may be poorly represented by energy maximisation, animal state plays an important part in determining intake and animals spend much of their lives well within the ultimate limits to action. If the benefit of a course of action, such as eating, does not increase linearly with the performance of that action, then there is a strong case for taking a costbenefit approach to analysing the optimal policy. Fitness benefits are actually rather unlikely to be a linear function of food intake (see Owen-Smith, 1994). A cost-benefit model would recognise that foraging and food intake have fitness costs as well as benefits. Foraging costs might increase progressively with food intake, and the optimal diet would maximise the difference between benefits and costs. Here, the cost and benefit functions would constrain the solution, but fixed constraints would not necessarily have to be invoked. The costs of food intake can be placed into two classes: extrinsic costs associated with the activity of foraging; costs intrinsic to food intake itself. Yearsley et al. (2002) have shown that these two classes of cost lead to fundamental differences in the predicted food intake behaviour.

\section{Extrinsic foraging costs of food intake}

Most of the extrinsic costs relate to the increase in foraging time associated with an increase in food intake or the selection of a more desirable diet (Table 2). An increase in foraging time may increase the risk of exposure to predators, prolong the time an animal is exposed to adverse weather conditions or decrease the time available for other activities (e.g. territorial defence, courtship).

Of all these costs, that associated with the exposure to predators is the easiest to manipulate and has immediate consequences for the forager. It has, therefore, been the subject of intensive study over the past decade (for reviews, see Lima \& Dill, 1990; Lima, 1998). Simple foraging models show that, under predation risk, animals should maximise food intake per unit predation risk (for example, see Gilliam \& Fraser, 1987; Houston et al. 1993). This optimal strategy is a mixture of the standard intake rate maximisation strategy and a strategy that tries to minimise the costs associated with foraging. Studies on insects (for example, see Scrimgeour \& Culp, 1994; Stoks \& Johansson, 2000; Dukas, 2001; McPeek et al. 2001), birds (for example, see Ghalambor \& Martin, 2001; Lambrechts et al. 2000) and fish (for example, see Gilliam \& Fraser, 1987; Lankford et al. 2001; Reznick et al. 2001) have all shown that an animal's foraging behaviour depends on its perceived level of predation risk, and that the theoretical predictions are broadly supported. Moreover, many of these responses to predation risk can only be understood by examining the consequences of predation for the whole life history of the animal. These results show that foraging behaviour can be adapted to the costs of foraging, although it remains to be seen whether this type of response can be generalised to other costs of foraging.

\section{Intrinsic costs of food intake}

Intrinsic costs of food intake are directly associated with the food source. For instance, the presence of toxins, parasite contamination or metabolic costs of food processing are all possible intrinsic costs of food intake. In contrast to extrinsic food intake costs, intrinsic costs can give rise to an optimal food intake which is sub-maximal (Yearsley et al.

Table 2. Some costs of foraging and food intake

\begin{tabular}{lll}
\hline Cause & Effect & Reference \\
\hline $\begin{array}{l}\text { Extrinsic costs } \\
\text { Time spent foraging }\end{array}$ & Reduced anti-predator vigilance \\
& $\begin{array}{l}\text { Greater exposure to predators } \\
\text { Reduced opportunity to find mate } \\
\text { Less sleep and rest }\end{array}$ & $\begin{array}{l}\text { Houston \& McNamara (1999) } \\
\text { Houston \& McNamara (1999) } \\
\text { Stephens \& Krebs (1986) }\end{array}$ \\
& Reduced time for territorial defence & McFarland (1989) \\
& Greater exposure to weather & Krebs \& Davies (1987) \\
& & Duncan et al. (2001) \\
Intrinsic costs & Less chance of escaping predators & Witter \& Cuthill (1993) \\
Increassed digesta load or lipid stores & Cost of detoxification & Illius \& Jessop (1995) \\
Ingestion of toxins & Hutchings et al. (1999) \\
Exposure to parasites & Infection & Skogland (1988) \\
Dental wear & Decreased foraging lifespan & Masoro (2000) \\
\hline
\end{tabular}


2002). Intrinsic costs are, therefore, of interest because they potentially provide a cost-benefit explanation of food intake regulation. The model of Yearsley et al. (2002) also demonstrates that an animal's life history will affect the importance of intrinsic costs for intake regulation. Intrinsic costs are predicted to depress food intake to a greater extent in longlived animals, whilst semelparous animals are more likely to have constrained food intake for all but the most hazardous foods (Fig. 2). Optimal food intake may also be expected to increase through the lifetime of a long-lived multiparous animal (Fig. 3). An animal is expected to support a greater

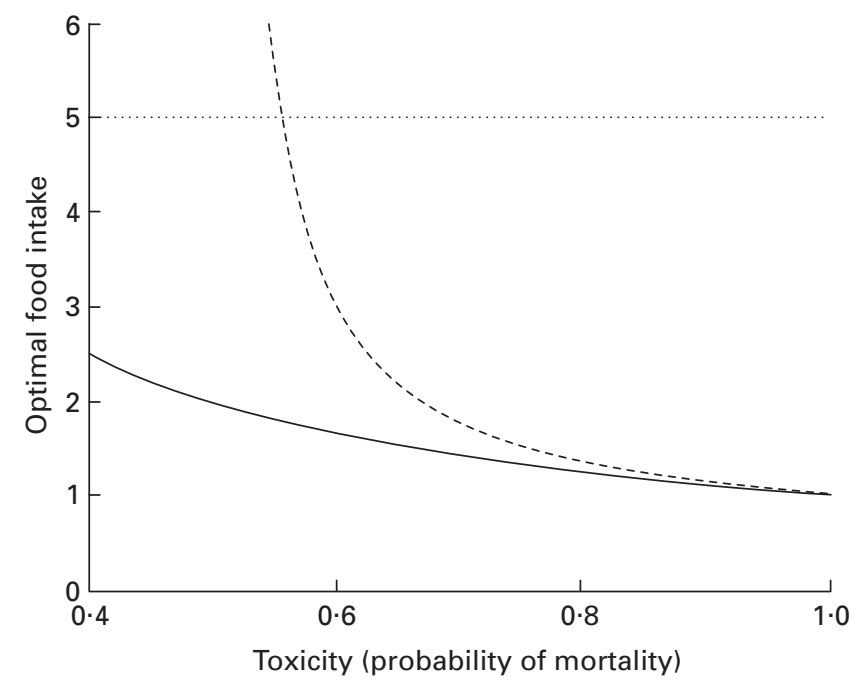

Fig. 2. The optimal food intake per breeding cycle in units of maintenance requirements for semelparous $(--)$ and iteroparous (-) animals as a function of the food's toxicity. (.......). An imagined upper limit (or constraint) for food intake. At low toxicities the semelparous animal will have a constrained food intake because the optimal intake exceeds the upper limit. All results assume no other foraging costs.

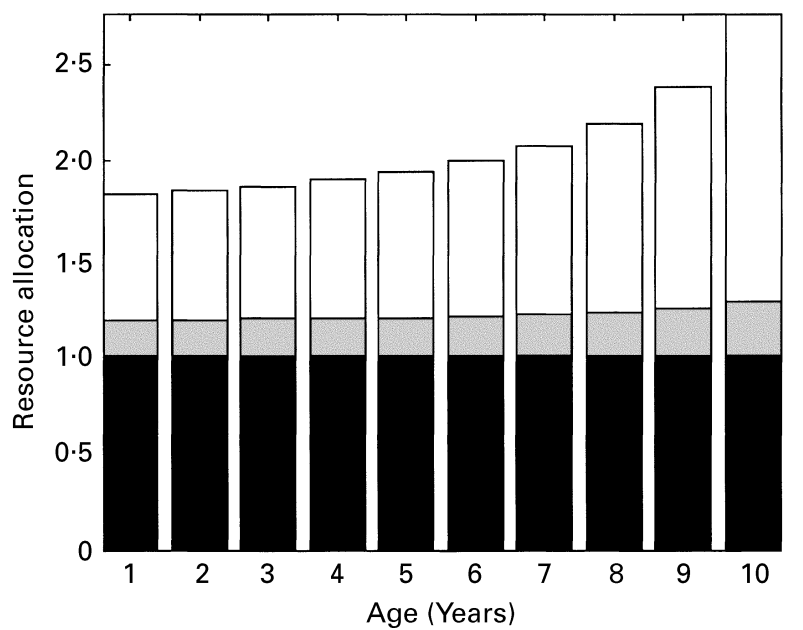

Fig. 3. The optimal allocation strategy to maintenance $(\boldsymbol{\square})$, defence mechanisms ( and reproduction $(\square)$ as a function of age for an iteroparous animal with a maximum of ten breeding cycles. Units of food intake are based on maintenance requirements. As the final breeding cycle approaches, food intake increases up to the level predicted for a semelparous organism. cost as it approaches the end of its reproductive lifespan, and the future reproductive opportunities decrease. Changes in other factors, such as the efficiency of food assimilation, may change the picture of food intake, but the pattern of an increasing cost tolerance with age is expected to be generic for animals with a finite reproductive lifespan (Houston \& McNamara, 1999).

Despite the growing body of circumstantial evidence suggesting that oxidative damage is an important intrinsic cost of food intake, little quantitative information is available on the direct link between increasing food intake and an increasing evolutionary cost. High food intakes result in high levels of oxidative metabolism and may lead to very high levels of lipid stores in the longer term (obesity), especially in mature animals. Both factors have been associated with degenerative neurological diseases, cardiovascular disease, diabetes, hypertension and the occurrence of tumours (for example, see Ketelaars \& Tolkamp, 1996; Friedman, 1998; Stubbs, 1998; Finkel \& Holbrook, 2000). Energy expenditure via $\mathrm{O}_{2}$ consumption elevates the production of oxygen free-radical species which are known to result in damage to organic molecules such as lipids, proteins and DNA, resulting in a gradual loss of vitality, physiological attrition of functionality (ageing) and a limited lifespan (Beckman \& Ames, 1998; Finkel \& Holbrook, 2000; Miquel, 2001; Moskovitz et al. 2002). Interestingly, a link has been suggested between the contribution of macronutrients to oxidative metabolism and their satiating effect and intake (for example, see Friedman, 1998; Stubbs, 1998; Stubbs \& O’Reilly, 2000).

Recent work on energy restriction in species ranging from nematodes and fruit flies (Drosophila melanogaster) to rodents and primates all show that restrictions in food intake to levels lower than ad libitum have beneficial effects on the occurrence of oxidative damage, disease, loss of vitality and maximum lifespan (Lane, 2000; Masoro, 2000; Roth et al. 2000; Finkel \& Holbrook, 2000; Lane et al. 2001). The favoured explanation of this phenomenon is that energy restriction acts by reducing oxidative stress (Sohal $\&$ Weindruch, 1996; Masoro, 2000; Ramsey et al. 2000; Finkel \& Holbrook, 2000). For simpler organisms like nematodes and fruit flies it is now clear that an increase in antioxidant defence systems via genetic modification can markedly postpone the age at which degenerative diseases, loss of vitality and senescence occur (Orr \& Sohal, 1994; Finkel \& Holbrook, 2000). This finding strongly suggests a direct causal effect of reactive oxygen species on future vitality and fitness. If increased food intake causes increased oxidative metabolism and oxidative damage, then this response represents a clear intrinsic cost of food intake. At present, it is not clear how this cost can be translated accurately into models that predict food intake, because many of the underlying relationships remain unquantified.

Tolkamp \& Ketelaars (1992) developed a simple costbenefit model for mature non-reproducing sheep that was based on the assumption that animals would try to maximise the benefits (in this case net energy intake) per unit costs (1 litre $\mathrm{O}_{2}$ consumed). This 'maximisation of efficiency of $\mathrm{O}_{2}$ utilisation' model gave accurate predictions of the observed variation in intake of mature sheep with access to different-quality foods (Tolkamp \& Ketelaars, 1992; 
Ketelaars \& Tolkamp, 1996). In a number of studies with animals in the wild, similar 'efficiency maximisation models' have given good predictions of observed foraging behaviour (for example, see Montgomerie et al. 1984; Schmid-Hempel et al. 1985; McLaughlin \& Montgomerie, 1990; Welham \& Ydenberg, 1993; Rasheed \& Harder, 1997; Biesmeijer \& Toth, 1998). In several of these studies (Schmid-Hempel et al. 1985; Tolkamp \& Ketelaars, 1992; Rasheed \& Harder, 1997; Biesmeijer \& Toth, 1998) it was assumed that energy expenditure (or oxidative metabolism) in the short-term represented an irreversible loss of future 'productivity'. If energy expenditure incurs costs that reduce lifespan, it would be expected that maximisation of shortterm efficiency would indeed maximise lifetime fitness.

Models which incorporate intrinsic costs (Yearsley et al. 2002) can be extended to look at the optimal resource allocation to protection against the deleterious effects of these costs. Examples of possible protection mechanisms are antioxidant production, cell repair and the mounting of an immune reaction. These extended models still predict a sub-maximal food intake provided that allocation to protection shows diminishing returns. Fig. 3 shows the predicted allocation to maintenance, reproduction and protection as a function of an animal's age. Unlike most traditional allocation models, resource allocation to protection need not decrease as allocation to reproduction increases, because food intake is not constrained. The result of a cost-benefit model for food intake is to make resource allocation and acquisition interdependent.

In all these studies, costs were measured or estimated from energy expenditure (or $\mathrm{O}_{2}$ consumption) and benefits were measured in a single currency (food or energy or protein). It is, however, at present not easy to extend this approach to other types of animals (for example, see young and growing or reproducing animals) for which the immediate benefits cannot easily be expressed in a single currency. It is even more difficult to estimate the (lifetime) fitness consequences of foraging decisions of an animal at a given physiological state.

\section{The effects of changing environments and genotypes}

Most livestock and humans now live lives abstracted from the conditions under which their species evolved. To a greater or lesser extent, the modern environment offers ready or controlled access to foodstuffs, with fewer attendant risks and costs of foraging. Livestock feeds generally are designed to be more nutrient-dense and require less work than natural forage. Similarly, humans are faced with an abundance of nutritionally-unbalanced foods, and a greatly reduced need for energy expenditure. Yet livestock and humans alike bring to these modern environments the goals, needs and faculties that evolved to maximise fitness in natural environments. In modern controlled environments they may continue to consume large amounts of energy, show positive energy balances and become obese (for example, see Searle et al. 1972; Blaxter et al. 1982; Ogink, 1993). High energy intake and obesity are detrimental, rather than beneficial, for future fitness, as judged from their effects on the occurrence of diseases and on life expectancy (Mela \& Rogers, 1998; Stubbs \& O’Reilly, 2000). Appar- ently, animals continue to use cues from their food and foraging that were a part of a previously-successful foraging strategy which, in modern conditions, is counterproductive.

Unlike most animal species, poultry have experienced rapid genetic change to the new environment of industrial meat production. Modern broilers are still slaughtered at comparable weights to 50 years ago. Intensive artificial selection has increased food intake relative to body mass, and has produced birds that now grow about four times faster, have greater muscle mass and an average age of slaughter of about 6 weeks (Emmans \& Kyriazakis, 2000). However, selection for high juvenile growth rates has created problems in other parts of the life cycle. Broilerbreeders (i.e. the parent stock) start producing eggs at about 20 weeks. Increased muscle mass has been at the expense of other organs and tissues. Given unlimited access to food, they continue to grow fast, resulting in a number of serious problems such as leg-weakness, heart failure and low reproductive capacity (Mench, 1993; Hocking \& McCormack, 1995). Clearly, these animals are 'fit' in the context of the production system until slaughter age, but not thereafter. Being under constant selection in a constant environment, they may indeed live 'at the edge of their solution space' for much of the time. This factor may explain the success of constraint-based models in the prediction of food intake for such animals (for example, see Emmans, 1997).

\section{Conclusions}

Animals are often thought of either as eating as much as they can, subject to some upper constraint, or to be matching their intake with a schedule of requirements. Although these views can provide useful predictions of food intake if the conditions are well known, neither view takes sufficient account of the costs of food intake as a force in the evolution of mechanisms controlling food intake. There are sound theoretical reasons why animals should have evolved mechanisms to control food intake at sub-maximal quantities. Such mechanisms would be expected to have evolved to balance the costs of food intake with the lifetime schedule of benefits (i.e. survival, growth, reproduction).

The conventional assumption that fitness is maximised by maximising daily food intake, subject to physical and physiological constraints, has been challenged by our research. Instead, we argue that fitness is maximised by balancing benefits and costs over the organism's lifetime. Fitness is the common currency for analysing and comparing benefits and costs. The fitness benefits of food intake are a function of its contribution to survival, growth (including necessary body reserves) and reproduction. Against these benefits must be set extrinsic and intrinsic costs of food intake.

Although many of the potential benefits of food intake, such as growth and reproduction, can be estimated from energy and nutrient intake, others, such as the ability to mount an immune response, are not well characterised. The relationships between food intake and costs and benefits probably vary in functional form between different types of costs and benefits. In aggregate, they comprise the fitness function of food intake. Analysis of the way that fitness varies with energy intake, as a result of the aggregate effect 
of its costs and benefits, must be the subject of future work that links theory with experimentation.

\section{Acknowledgements}

This work was supported by the Scottish Executive Rural Affairs Department.

\section{References}

Allen MS (1996) Physical constraints on voluntary intake of forages by ruminants. Journal of Animal Science 74, 3063-3075.

Beckman KB \& Ames BN (1998) The free radical theory of aging matures. Physiological Reviews 78, 547-581.

Belovsky GE (1978) Diet optimization in a generalist herbivore: the moose. Theoretical Population Biology 14, 105-134.

Belovsky GE (1994) How good must models and data be in ecology? Oecologia 100, 475-480.

Belovsky GE, Fryxell J \& Schmitz OJ (1999) Natural selection and herbivore nutrition: optimal foraging theory and what it tells us about the structure of ecological communities. In Vth International Symposium on the Nutrition of Herbivores, pp. 1-70 [H-JG Jung and GC Fahey Jr, editors]. Savoy, IL: American Society of Animal Science.

Belovsky GE \& Schmitz OJ (1993) Owen-Smith's evaluation of herbivore foraging models: what is constraining? Evoutionary Ecology 7, 525-529.

Biesmeijer JC \& Toth E (1998) Individual foraging, activity level and longevity in the stingless bee Melipona beecheii in Costa Rica (Hymenoptera, Apidae, Meliponinae) Insectes Sociaux $\mathbf{4 5}$, 427-443.

Blaxter KL, Fowler VR \& Gill JC (1982) A study of the growth of sheep to maturity. Journal of Agricultural Science, Cambridge 98, 405-420.

Dukas R (2001) Effects of perceived danger on flower choice by bees. Ecology Letters 4, 327-333.

Duncan AJ, Mayes RW, Young SA, Lamb CS \& MacEachern P (2001) Choice of foraging patches by hill sheep given different opportunities to seek shelter and food. Animal Science 73, 563-570.

Emmans GC (1997) A method to predict the food intake of domestic animals from birth to maturity as a function of time. Journal of Theoretical Biology 186, 189-199.

Emmans GC \& Kyriazakis I (2000) Issues arising from genetic selection for growth and body composition characteristics in poultry and pigs. In The Challenge of Genetic Change in Animal Production. Occasional Publication of the British Society of Animal Science no.27, pp. 39-53. Edinburgh: British Society of Animal Science.

Finkel T \& Holbrook NJ (2000) Oxidants, oxidative stress and the biology of ageing. Nature 408, 239-247.

Friedman MI (1998) Fuel partitioning and food intake. American Journal of Clinical Nutrition 67, 513S-518S.

Ghalambor CK \& Martin TE (2001) Fecundity-survival trade-offs and parental risk taking in birds. Science 292, 494-497.

Gilliam JF \& Fraser DF (1987) Habitat selection under predation hazard: test of a model with foraging minnows. Ecology $\mathbf{6 8}$, $1856-1862$.

Gross JE, Alkon PU \& Demment MW (1996) Nutritional ecology of dimorphic herbivores: Digestion and passage rates in Nubian ibex. Oecologia 107, 170-178.

Hocking PM \& McCormack HA (1995) Differential sensitivity of ovarian follicles to gonadotrophin stimulation in broiler and layer lines of domestic fowl. Journal of Reproduction and Fertility 105, 49-55.

Houston AI \& McNamara JM (1999) Models of Adaptive Behaviour. Cambridge: Cambridge University Press.

Houston AIJ, McNamara M \& Hutchinson JMC (1993) General results concerning the trade-off between gaining energy and avoiding predation. Philosophical Transactions of the Royal Society of London 341B, 375-397.

Hutchings MR, Kyriazakis I, Gordon IJ \& Jackson F (1999) Tradeoffs between nutrient intake and faecal avoidance in herbivore foraging decisions: the effect of animal parasitic status, level of feeding motivation and sward nitrogen content. Journal of Animal Ecology 68, 310-323.

Illius AW \& Gordon IJ (1999) Physiological ecology of mammalian herbivory. In Vth International Symposium on the Nutrition of Herbivores, pp. 71-96 [H-JG Jung and GC Fahey Jr, editors]. Savoy, IL: American Society of Animal Science.

Illius AW \& Jessop NS (1995) Modelling metabolic costs of allelochemical ingestion by foraging herbivores. Journal of Chemical Ecology 21, 693-719.

Ketelaars JJMH \& Tolkamp BJ (1996) Oxygen efficiency and the control of energy flow in animals and man. Journal of Animal Science 74, 3036-3051.

Krebs JR \& Davies NB (1987) An Introduction to Behavioural Ecology. Oxford: Blackwell Scientific Publications.

Lambrechts MM, Prieur B, Caizergues A and Dehorter O \& Galan M-J \& Perret P (2000) Risk-taking restraints in a bird with reduced egg-hatching success. Proceedings of the Royal Society of London 267B, 333-338.

Lane MA (2000) Nonhuman primate models in biogerontology. Experimental Gerontology 35, 533-541.

Lane MA, Black A, Handy A, Tilmont EM, Ingram DK \& Roth GS (2001) Caloric restriction in primates. Healthy Aging for Functional Longevity 928, 287-295.

Lankford TE Jr, Billerbeck JM \& Conover DO (2001) Evolution of intrinsic growth and energy acquisition rates. II. Trade-offs with vulnerability to predation in Menidia menidia. Evolution 55, 1873-1881.

Lima SL (1998) Stress and decision making under the risk of predation: Recent developments from behavioral, reproductive, and ecological perspectives. Advances in the Study of Behaviour 27, 215-290.

Lima SL \& Dill LM (1990) Behavioural decisions made under the risk of predation: a review and prospectus. Canadian Journal of Zoology 68, 619-640.

McFarland D (1989) Problems of Animal Behaviour. Harlow, Essex: Longman Scientific and Technical.

McLaughlin RL \& Montgomerie RD (1990) Flight speeds of parent birds feeding nestlings: maximisation of foraging efficiency or food delivery rate? Canadian Journal of Zoology 68, 2269-2274.

McPeek MA, Grace M \& Richardson JML (2001) Physiological and behavioural responses to predators shape the growth/predation risk trade-off in damselflies. Ecology 82, $1535-1545$.

Masoro JE (2000) Caloric restriction and aging: an update. Experimental Gerontology 35, 299-305.

Mela DJ \& Rogers PJ (1998) Food, Eating and Obesity. The Psychobiological Basis of Appetite and Weight Control. London: Chapman \& Hall.

Mench JA (1993) Problems associated with broiler breeder management. In Proceedings of the Fourth European Symposium on Poultry Welfare, pp. 195-207 [CJ Savory and BO Hughes, editors]. Potters Bar, Herts.: Universities Federation for Animal Welfare.

Miquel J (2001) Nutrition and ageing. Public Health Nutrition 4, $1385-1388$. 
Montgomerie RD, Eadie JM \& Harder LD (1984) What do foraging hummingbirds maximize? Oecologia 63, 357-363.

Moskovitz J, Yim MB \& Chock PB (2002) Free radicals and disease. Archives of Biochemistry and Biophysics 397, 354-359.

Ogink MWM (1993) Genetic size and growth in goats. PhD Thesis, Wageningen Agricultural University, The Netherlands.

Orr WC \& Sohal RS (1994) Extension of life-span by overexpression of superoxidedismutase and catalase in Drosophila melanogaster. Science 263, 1128-1130.

Owen-Smith N (1993) Evaluating optimal diet models for an African browsing ruminant, the kudu: how constraining are the assumed constraints? Evolutionary Ecolology 7 530-531.

Owen-Smith N (1994) Foraging responses of kudus to seasonal changes in food resources: elasticity in constraints. Ecology $\mathbf{7 5}$ 1050-1062.

Owen-Smith N (1996) Circularity in linear programming models of optimal diet. Oecologia 108, 259-261.

Owen-Smith N (1998) How high ambient temperature affects the daily activity and foraging time of a subtropical ungulate, the greater kudu (Tragelaphus strepsiceros). Journal of Zoology 246, 183-192.

Pitroff W \& Kothman MK (1999) Regulation of intake and diet selection by herbivores. In Vth International Symposium on the Nutrition of Herbivores, pp. 366-422 [H-JG Jung and GC Fahey Jr, editors]. Savoy, IL: American Society of Animal Science.

Ramsey JJ, Harper ME \& Weindruch R (2000) Restriction of energy intake, energy expenditure, and aging. Free Radical Biology and Medicine 29, 946-968.

Rasheed SA \& Harder LD (1997) Foraging currencies for nonenergetic resources: pollen collection by bumblebees. Animal Behaviour 54, 911-926.

Reznick D, Butler MJ \& Rodd H (2001) Life-history evolution in guppies. VII. The comparative ecology of high and low predation environments. American Naturalist 157, 126-140.

Roth GS, Ingram DK, Black A \& Lane MA (2000) Effects of reduced energy intake on the biology of aging: the primate model. European Journal of Clinical Nutrition 54, S15-S20.
Schmid-Hempel P, Kacelnik A \& Houston AI (1985) Honeybees maximise efficiency by not filling their crop. Behavioral Ecology and Sociobiology 17, 61-66.

Scrimgeour GJ \& Culp JM (1994) Feeding while evading predators by a lotic mayfly: linking short-term foraging behaviours to longterm fitness consequences. Oecologia 100, 128-134.

Searle TW, Graham NM \& O'Callaghan M (1972) Growth in sheep. I. The chemical composition of the body. Journal of Agricultural Science, Cambridge 79, 371-382.

Skogland T (1988) Tooth wear by food limitation and its life history consequences in wild reindeer. Oikos 51, 238-242.

Sohal RS \& Weindruch R (1996) Oxidative stress, caloric restriction and aging. Science 237, 59-63.

Stephens DW \& Krebs JR (1986) Foraging Theory. Princeton, NJ: Princeton University Press.

Stoks R \& Johansson F (2000) Trading off mortality risk against foraging effort in damselflies that differ in life cycle length. Oikos 91, 559-567.

Stubbs RJ (1998) Appetite, feeding behaviour and energy balance in human subjects. Proceedings of the Nutrition Society 57, 1-16.

Stubbs RJ \& O'Reilly LM (2000) Carbohydrate and fat metabolism, appetite and feeding behavior in humans. In Neural and Metabolic Control of Macronutrient Intake, pp. 165-188 [H-R Berthoud and RJ Seeley, editors]. Boca Raton, FL: CRC Press.

Tolkamp BJ \& Ketelaars JJMH (1992) Toward a new theory of feed intake regulation in ruminants. 2. Costs and benefits of feed consumption: an optimization approach. Livestock Production Science 30, 297-317.

Welham CVJ \& Ydenberg RC (1993) Efficiency-maximising flight speeds in parent black terns. Ecology 74, 1893-1901.

Weston RH (1996) Some aspects of constraints to forage consumption by ruminants. Australian Journal of Agricultural Research 47, 175-197.

Witter MS \& Cuthill IC (1993) The ecological costs of avian fat storage. Philosophical Transactions of the Royal Society of London 340B, 73-92.

Yearsley JM, Hastings IM, Gordon IJ, Kyriazakis I \& Illius AW (2002) A lifetime perspective on foraging and mortality. Journal of Theoretical Biology 215, 385-397. 